\title{
Joseph Tulchin sobre a relação entre Estados Unidos e América Latina
}

\author{
Rejane Carolina Hoeveler ${ }^{1}$
}

\section{Joseph Tulchin on the relationship between the United States and Latin America}

Resenha de TULCHIN, Joseph S. América Latina x Estados Unidos. Uma relação turbulenta. São Paulo: Editora Contexto, 2016.

\section{Resenha recebida em: 21/12/2016}

Resenha aprovada em: 27/06/2017

O livro do historiador estadunidense Joseph Tulchin, recentemente lançado no Brasil, traz um panorama das relações entre América Latina e Estados Unidos desde o processo das independências até o presente, com foco na política externa adotada nos diferentes períodos históricos pelos Estados Unidos e pelos diversos países da América Latina, bem como das diferentes iniciativas de integração hemisférica desde o século XIX, após as independências, até os dias atuais. Tratando-se de uma narrativa factual bem escrita, com poucas notas e de fácil assimilação pelo leitor médio, a publicação tem o formato de um manual básico para estudantes de História e de Relações Internacionais, ora tratando diretamente das relações entre Estados Unidos e América Latina, ora trazendo uma história comparativa dos processos políticos no hemisfério. A maior parte das referências utilizadas pelo autor é de autores norte-americanos, havendo pouca interação com a produção historiográfica latino-americana sobre os diversos temas históricos tratados na obra.

Joseph Tulchin é PhD em História pela Universidade Harvard com especialização em América Latina, tendo sido professor das Universidades de Yale e Carolina do Norte; além de ter dirigido o tradicional Programa Latino-americano do Woodrow Wilson International Center for Scholars, em Washington. O trabalho de

\footnotetext{
${ }^{1}$ Mestre e doutoranda em História (PPGH/UFF), bolsista CNPq.

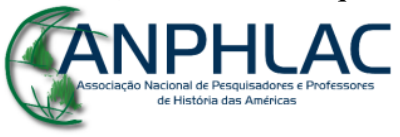

Revista Eletrônica da ANPHLAC, ISSN 1679-1061, №. 23, p. 314-319, Jul./Dez., 2017. http://revista.anphlac.org.br
} 
pesquisa mais relevante de sua carreira se concentra na história argentina do século $\mathrm{XX}$ e suas relações com os Estados Unidos (TULCHIN 1990).

A narrativa do livro se inicia no nascimento das repúblicas americanas, comparando semelhanças e diferenças nos processos de independência política no continente. O ponto mais importante aqui é a comparação que o autor faz sobre a importância que a "atenção no processo político" teria recebido ao Norte e ao Sul, e é precisamente sobre este ponto que podem ser levantadas as primeiras críticas acerca da leitura de Tulchin.

Segundo o autor, enquanto nos Estados Unidos uma preocupação com a "prestação de contas" ao povo levou a um foco no processo político entendido como um processo que devia ser "transparente", na América Latina os líderes dos movimentos de independência "não buscaram evitar as armadilhas de uma formulação autoritária do processo político" (TULCHIN, 2016, p. 23). Uma certa tendência ao autoritarismo fica, assim, implícita na leitura de Tulchin sobre a formação política na América Latina, em contraste com a vibrante democracia dos Estados Unidos. ${ }^{2}$

Essa diferença histórica nos processos de independência teria gerado duas culturas de política externa muito distintas. Enquanto nas treze colônias do Norte teria se consolidado desde o início uma visão "pragmática" e "realista" de política externa, na qual já se entendia o novo país como uma peça importante no jogo mundial, entre os líderes das independências latino-americanas teria predominado uma "ideia universalista de uma irmandade de homens", mais oriunda da revolução francesa (TULCHIN, 2016, p. 21). No entanto, pouco apoio local e muita instabilidade política dificultavam uma política externa mais potente para os últimos países.

Embora utilize várias vezes os termos "hegemonia" e "imperialismo" para se referir à relação histórica entre EUA e América Latina, o autor não chega a conceituar ou mesmo a adotar uma conceitualização explícita acerca deles. Em algumas passagens, Tulchin afirma que se trata de uma espécie de acusação dos latino-americanos contra os

\footnotetext{
${ }^{2}$ É de se notar que quando trata da independência dos Estados Unidos o autor se utilize frequentemente de tons apologéticos, como quando discorre sobre a "civilidade" e "sabedoria" de figuras como Jefferson e Madison, a "racionalidade" e o "realismo" de Washington e Hamilton (TULCHIN, 2016, p. 23), ou quando ressalta a tolerância como uma característica central da "cultura de povoamento" estabelecida nas 13 colônias (TULCHIN, 2016, p. 16).
}

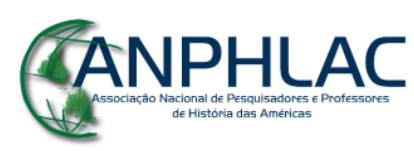

Revista Eletrônica da ANPHLAC, ISSN 1679-1061, №. 23, p. 314-319, Jul./Dez., 2017. http://revista.anphlac.org.br 
Estados Unidos, que, como toda versão parcial ou maniqueísta, deve ser criticada. $^{3}$ Outras vezes, a "hegemonia" aparece como um fato inconteste, mas não porque tenha sido "imposta" e sim adquirida/conquistada, seja por conta de estratégias políticas mais inteligentes dos EUA, seja por conta de certo imediatismo ou mesquinhez política das elites latino-americanas, que muitas vezes procuraram simplesmente manipular suas relações nacionais com os EUA para manter ou conquistar posições políticas internas. Uma suposição bastante questionável dessa explicação é que a relação com a América Latina nunca teria sido muito importante na política dentro dos EUA, não havendo nenhum comentário mais detido sobre esse aspecto em todo o livro.

Outro ponto bastante enfatizado por Tulchin é sobre o "engano" histórico que teria sido cometido pela "versão" latino-americana acerca da Doutrina Monroe, como uma primeira asserção do imperialismo norte-americano no continente. Em sua explicação, Tulchin dá mais peso a esse "engano" do que ao fato de que a própria Doutrina Monroe fora usada posteriormente para a justificação de intervenções imperialistas, como ele mesmo reconhece. Contrapondo-se a uma visão sobre a relação dos EUA com a América Latina que se centra na questão da dominação, Tulchin enfatiza uma "dificuldade em exercer protagonismo" por parte dos governos latinoamericanos, a maior parte da qual pode ser atribuída a si mesmos, como sua suposta "inabilidade de priorizar os interesses nacionais e de imaginar uma identidade nacional" (TULCHIN, 2016, p. 30). Segundo Tulchin, "a diferença entre Norte e Sul era que os EUA, apesar de sua fraqueza, sentiam que tinham algum poder no sistema internacional, e nunca deixaram de exercer seu protagonismo" (TULCHIN, 2016, p. 31). Nesse sentido, vale destacar que Tulchin apoia-se na visão do diplomata chileno Heraldo Muñoz, segundo a qual, mais importante do que o poder de uma nação, seria "como ela explora sua cota de poder para potencializar seus interesses nacionais" (MUÑOZ, 1982). ${ }^{4}$

\footnotetext{
3 "Segundo a versão latino-americana dessa narrativa, os Estados Unidos impuseram uma hegemonia sobre a América Latina" (TULCHIN, 2016, p. 27).

${ }^{4}$ Note-se que "interesses nacionais" são tomados pelo autor como homogêneos e em nenhum momento são colocadas mais profundamente questões relativas a classes ou frações sociais.
}

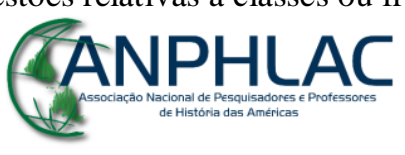

Revista Eletrônica da ANPHLAC, ISSN 1679-1061, №. 23, p. 314-319, Jul./Dez., 2017. http://revista.anphlac.org.br 
Os capítulos sobre o período da chamada "Diplomacia do Dólar", sobre as duas Guerras Mundiais e sobre a Guerra Fria trazem informações interessantes acerca da formulação de política externa em Washington, com enfoque nas relações políticas e, por vezes, pessoais entre diplomatas estadunidenses e líderes latino-americanos. Pouco ou nenhum espaço é dado, entretanto, a uma análise da relação dessas políticas com interesses econômicos, mesmo nos momentos em que o livro trata de golpes militares que sabidamente foram dados com o apoio de empresas americanas.

A orientação teórica e política do autor fica mais clara quando este trata da CEPAL, da teoria da dependência e da história econômica da América Latina entre os anos 1930 e 1990, quando coloca a economia do Brasil sob Vargas e da Argentina sob Perón sob a rubrica de "economias de semi-comando" que estavam fadadas ao fracasso devido a uma visão "estatista" e ultrapassada das relações econômicas internacionais. Nesse ponto, é possível observar, em primeiro lugar, que o autor confunde a teoria da dependência com a teoria da CEPAL, tratando-as como se fossem a mesma corrente, e obliterando o debate crítico que existiu entre essas diferentes escolas de pensamento (TULCHIN, 2016, p. 77-8). ${ }^{5}$

Segundo Tulchin, "Com o tempo, a ineficácia dessa economia, juntamente a níveis exorbitantes de corrupção, ao protecionismo sindical e a tomadas de decisão de curto prazo, tornou-a não competitiva" (TULCHIN, 2016, p. 77), atribuindo à crise da dívida, dos anos 1980, as características inerentes ao modelo "estatista", sem nenhuma referência a elementos factuais largamente entendidos como relevantes na crise da dívida, como a alta dos juros do Banco Central americano em 1979.

Não é difícil perceber que esse é precisamente o diagnóstico do discurso neoliberal que predominou no pensamento econômico e nas instituições multilaterais mais importantes durante a década de 1990 (MENDES PEREIRA, 2010; RANGEL; GARMENDIA, 2012). Segundo esse discurso, a "abertura" comercial e econômica da América Latina era inevitável; o fracasso da política de substituição de importações era

\footnotetext{
${ }^{5}$ É sabido na literatura especializada que tanto em sua vertente estrutural-funcionalista de Enzo Faletto e Fernando Henrique Cardoso, como em sua vertente marxista (Ruy Mauro Marini, Theotonio dos Santos, Vânia Bambirra, entre outros), a teoria da dependência criticava abertamente o modelo da CEPAL, vista pelos teóricos dependentistas como dualista. Uma das mais importantes críticas tanto à teoria cepalina quanto à teoria da dependência da versão FHC-Faletto pode ser encontrada em OLIVEIRA (2003).
}

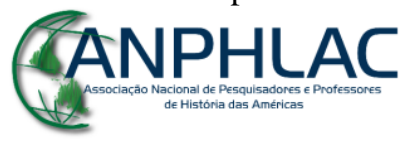

Revista Eletrônica da ANPHLAC, ISSN 1679-1061, №. 23, p. 314-319, Jul./Dez., 2017. http://revista.anphlac.org.br 
"previsível"; a causa das crises econômicas latino-americanas estaria quase sempre em algum tipo de "excesso de intervenção" do Estado, e a única saída possível para ela seria estar mais abertura ao mercado internacional. Outro elemento central nessa visão está na identificação entre nacionalismo e autoritarismo, enquanto a "governança democrática" está necessariamente associada a uma "economia de livre mercado" (TULCHIN, 2016, p. 81). A "competitividade", termo usualmente empregado no lugar de “capitalismo", é encarada como um valor básico, natural e inquestionável. Note-se também que a problemática da accountability, que, como vimos anteriormente, é um aspecto central da análise de Tulchin sobre a independência americana, emerge justamente nesse período, geralmente deslocando a questão da participação popular na análise de vários temas sociais. ${ }^{6}$

Dessa forma, não surpreende que os capítulos dedicados ao pós-Guerra Fria sejam abertamente apologéticos da entrada dos países da América Latina na chamada "globalização", com "políticas econômicas que os tornavam mais transparentes e mais competitivos no mercado internacional" (TULCHIN, 2016, p. 125); e com o “entusiasmo na América Latina por um comércio mais livre e por regras trabalhistas e ambientais negociadas" (TULCHIN, 2016, p. 135). Entendido este "lugar de fala" do autor, também não chega a causar espanto os elogios rasgados ao economista John Williamson, reconhecido pelo próprio Tulchin como formulador do "Consenso de Washington"; e, até mesmo, aos governos de Fernando Henrique Cardoso [1995-2002], o qual teria tido "sucesso rápido e surpreendente" quando possibilitou a formação de joint ventures com a Petrobrás e quando privatizou "uma série de outras companhias públicas que obstaculizavam o desenvolvimento do país", medidas que fizeram "a economia decolar" e com ela, um "novo protagonismo" brasileiro no mundo (TULCHIN, 2016, p. 149). Na época de Fernando Henrique, de acordo com Tulchin, “o país estava no caminho certo, conduzido por uma série de ministros das Relações Exteriores ambiciosos e competentes” (TULCHIN, 2016, p. 149-150).

\footnotetext{
${ }^{6}$ A redução da problemática da participação popular à questão da accountability é apontada por Dardot e Laval como um dos aspectos antidemocráticos da racionalidade governamental neoliberal (DARDOT; LAVAL, 2016).
}

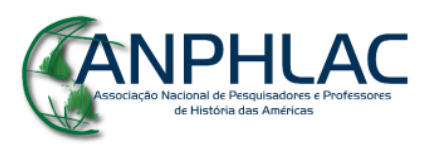

Revista Eletrônica da ANPHLAC, ISSN 1679-1061, №. 23, p. 314-319, Jul./Dez., 2017. http://revista.anphlac.org.br 
Em suma, se por um lado podemos afirmar que se trata de uma obra relevante, não apenas pela importância do tema, mas também pela inquestionável capacidade de síntese do autor, por outro, é importante perceber que não se trata de uma obra isenta de ideologia e de posição política, como de certa forma parece sugerir a apresentação à edição brasileira. Ao contrário, como procuramos apontar, é preciso localizar a interpretação de Tulchin sobre as relações entre Estados Unidos e América Latina em uma chave de leitura que se propõe a revisar as teses que historicamente embasaram políticas de caráter anti-imperialista por parte dos mais diversos países latinoamericanos, apresentando como alternativa uma visão que compartilha dos pressupostos do pensamento neoliberal acerca da política, da economia e das relações internacionais.

\section{Referências Bibliográficas}

DARDOT, Pierre; LAVAL, Christian. A nova razão do mundo. Ensaio sobre a sociedade neoliberal. São Paulo: Boitempo, 2016.

MENDES PEREIRA, João Márcio. O Banco Mundial como ator político, intelectual e financeiro (1944-2008). Rio de Janeiro: Civilização Brasileira, 2010.

MUÑOZ, Heraldo. The strategic dependency of the centers and the economic importance of the Latin American periphery. LARR, n ${ }^{\mathrm{o}}$ 16, v. 3, p. 3-29, 1982.

OLIVEIRA, Francisco de. Crítica da razão dualista. São Paulo: Boitempo, 2003 [1972].

RANGEL, Rubi Martinez; GARMENDIA, Ernesto Solo Reyes. El Consenso de Washington: la instauración de las políticas neoliberales em America Latina. Política y Cultura, n ${ }^{0}$ 37, p. 35-64, 2012.

TULCHIN, J. Argentina and the United States. A conflicted relationship. Boston: Twayne, 1990.

\section{CANPHLAC}

Revista Eletrônica da ANPHLAC, ISSN 1679-1061, №. 23, p. 314-319, Jul./Dez., 2017.

http://revista.anphlac.org.br 